\title{
Grandes riesgos e información tergiversada e incompleta $\left.{ }^{*}\right)$
}

\section{Big risks and misrepresented and incomplete information}

\author{
Alonso Núñez del Prado Simons ${ }^{(*)}$ \\ Universidad Católica de Santa María de Arequipa
}

\begin{abstract}
Resumen: El autor analiza el concepto de 'grandes riesgos', de origen europeo que ha sido y pretende ser mal utilizado en Latinoamérica. Defiende la alternativa legislativa por la que se optó en la ley de contrato de seguro de Perú, donde se estableció una especie de control difuso en vez del establecimiento de montos que delimiten la barrera. Critica el Proyecto de ley presentado en el Congreso peruano que pretende imitar el camino chileno.
\end{abstract}

Palabras clave: Grandes riesgos - normas indisponibles - control difuso Solvencia II - consumidores - pequeñas empresas - interpretación contra stipulatorem

\begin{abstract}
The author analyzes the European concept of 'Large Risk', a subject which has been misunderstood in Latin America. He defend the Peruvian alternative that prefer the Judicial Review instead of the amount limits; and criticize the Project presented in the Peruvian Congress which pretends the second one, following the Chilean law that has deformed -in his opinion- the original (European) idea.
\end{abstract}

Key words: Large risk - Unavailable rules - Judicial Review - Solvency II Consumers - Small business - Against stipulatorem interpretation

(*) Nota del Editor: Este artículo fue recibido el 16 de octubre de 2017 y su publicación fue aprobada el 10 de noviembre de 2017.

${ }^{* *}$ Abogado por la Universidad Católica de Santa María de Arequipa donde también cursó el Magíster en Derecho de la Integración, es Master of Business Administration (MBA) por el College of Insurance de Nueva York, graduado en Lingüística y Literatura, además de en Filosofía, en que también cursó el Magíster así como la Maestría en Derecho Constitucional, todo en la Pontificia Universidad Católica del Perú (PUCP). Es fundador y Director Ejecutivo del Observatorio de cumplimiento de planes de gobierno, ha sido profesor universitario (PUCP, Universidad de Lima y Escuelas de Seguros de la APESEG y de APECOSE), árbitro y conferencista internacional (Lisboa, Santiago de Chile, La Habana y Santa Cruz de la Sierra). Es autor del libro 'Los secretos de los seguros' publicado por la PUCP y co-autor del libro 'Derecho de seguros y reaseguros' publicado por la Universidad Javeriana de Colombia. Publica habitualmente en revistas jurídicas y en los principales diarios de Lima. Asimismo, es Presidente de la Asociación Peruana de Derecho de Seguros, Capítulo de AIDA en el Perú, director de varias entidades del sistema asegurador y socio de Daly, Otero, Florez \& Núñez del Prado, Abogados. 
Grandes riesgos e información tergiversada e incompleta Big risks and misrepresented and incomplete information
Sumario: 1. Introducción_2. Definición de Grandes riesgos_3. Legislación comparada_3.1. La Unión Europea y España_3.2. Chile_3.3. El caso de Perú_4. El rol protector del Estado en el contrato de seguro_5. Referencias bibliográficas.

\section{Introducción}

Es necesario dejar claro que el Proyecto de ley 4635/2014CR sobre Grandes riesgos que si bien nunca llegó al Pleno del Congreso de la República fue porque discutido en la Comisión de Justicia se desenmascaró sus intenciones y perdió la votación. Lamentablemente eso no ocurrió cuando se aprobó y luego promulgó la Ley 29549 que prácticamente dejó sin posibilidad de tener cobertura de seguro de vida ley a los cesantes y jubilados.

\section{Definición de Grandes riesgos}

Para efectos del negocio de seguros una correcta definición de Gran riesgo sería el cliente o asegurado que tiene suficiente poder para negociar de igual a igual las condiciones del contrato con una aseguradora, que puede discutir los términos de la póliza de seguro como lo harían en cualquier otro contrato paritario de servicio dos partes sin que una pueda imponerse a la otra. Las otras definiciones tomadas de la legislación comparada tienen siempre como fundamento la que acabo de indicar. La razón por la que las normas europeas otorgan a los Grandes riesgos un tratamiento diferente es la definición que he resumido. Es cierto que en seguros la expresión Grandes riesgos no tiene el mismo significado en las diferentes legislaciones, pero intencionalmente se olvida su soporte racional que insisto es el ya mencionado. En otras palabras, definir a los Grandes riesgos a partir de las legislaciones de otros países es como sostener que las normas no tienen fundamentos, como describir las cosas por su apariencia y no por su sustancia.

Hay otro engaño soterrado y de contrabando en la supuesta intención de separar los Grandes riesgos de los otros y es que en el Perú (y en la mayor parte de países del mundo) en realidad hay (i) Grandes riesgos (muy pocos), (ii) riesgos medianos y los cubiertos por (iii) seguros personales, (iv) obligatorios y (v) masivos. La propuesta con la que se pretendió engañar al Congreso y a los peruanos, con el sospechoso apoyo de la Superintendencia de Banca Seguros y AFP (En adelante, "SBS"), intentaba obviar a los riesgos medianos que en el caso de nuestro país constituyen la parte más importante de los seguros generales en términos de primas. Estos últimos no tienen, a diferencia de los grandes riesgos, capacidad de negociar 'de igual a igual' con las compañías de seguros, es más por lo general las condiciones de sus pólizas son las pre-redactadas por éstas. En consecuencia, necesitan ser parte la protección de la Ley 29946 del contrato de seguro (En adelante, "LCS"). El proyecto de ley 4635/2014-CR pretendía que la SBS definiera lo qué son los Grandes riesgos sabiendo de antemano que ésta seguiría el ejemplo chileno del que nos ocuparemos más adelante.

Cabe entonces preguntarnos ¿por qué en algunas legislaciones los grandes riesgos tienen una aplicación y beneficios diferentes en las respectivas leyes de contrato de seguro? La respuesta es bastante obvia: en los casos de grandes riesgos la asimetría entre las partes no es tan acentuada como en los demás asegurados. La razón por la que en la mayor parte de países se regula el contrato de seguro es, como acabamos de señalar, por el desequilibrio entre asegurado y asegurador al celebrarse el contrato. Mientras el segundo es un experto en el negocio, el primero no lo conoce suficientemente, además que el último redacta el contrato (y lo va modificando y adecuando en el tiempo acorde con su experiencia y conveniencia). Carece de sustento afirmar que el monto de los activos asegurados, la asesoría de brókeres y corredores de seguros, sean del nivel que fueran, ni contar con un departamento de administración de riesgos consigan equilibrar la asimetría existente en el contrato de seguros, como lo demuestra el hecho de que en la mayoría de casos las pólizas de empresas importantes estén sometidas a los textos pre-redactados por las aseguradoras y las primeras no puedan lograr modificaciones significativas. 


\section{Alonso Núñez del Prado Simon}

De otro lado, muchas de las normas que regulan el contrato de seguros, que se conocen en la doctrina argentina como indisponibles (artículo 158 de la Ley 17418), son aplicables a los grandes riesgos porque éstos también contratan pólizas que tienen esa condición y una exclusión tan radical carece de sustento. Resulta más conveniente un control difuso y que en caso de litigio sea el juez o el árbitro el que determine qué partes de la ley de contrato de seguro son aplicables a los grandes riesgos en vez de excluirlos de plano con las consecuentes desventajas que resultan de que sea una cantidad o monto establecido por el organismo supervisor el que determine cuándo el contrato está dentro del campo de aplicación de la norma.

En Chile es un hecho comprobado que por este último camino resultan excluyéndose casos en los que el asegurado no ha tenido ninguna capacidad de negociación ${ }^{(1)}$ y por el contrario se ha visto obligado a aceptar las condiciones y textos pre redactados por el asegurador, es decir que el contrato ha continuado siendo por adhesión, y tal cosa es injusta e inaceptable. El enorme poder que tienen las compañías de seguros en el mundo presiona permanentemente para evitar la regulación, tanto que en el Perú algunos funcionarios de compañías de seguros y abogados, supuestamente expertos en el tema, llegaron a sostener públicamente durante el proceso de aprobación de la LCS, incluso en el Congreso de la República, que no era necesaria, aunque nunca pudieron responder a la contra pregunta: ¿Entonces, por qué los demás países la tienen?

Una de las clasificaciones de los contratos que hace la doctrina es la que los separa en paritarios o discrecionales cuando hay colaboración en su diseño entre las partes-y de adhesión o predispuestos, en el caso que una de las partes los redacta y la otra los acepta. Por razones bastante obvias a los segundos la ley les da un tratamiento diferente y así está contemplado en los artículos 1398-1401 de nuestro Código Civil y en el artículo 48 y otros del Código de Protección al Consumidor a los que hay que sumar el artículo 65 de la Carta Constitucional. Casi sin excepción los doctrinarios consideran que el contrato de seguro es de adhesión y en consecuencia goza de las protecciones establecidas en las normas antedichas además de las específicas señaladas en la Ley 29946 del contrato de seguro (LCS).

\section{Legislación comparada}

\subsection{La Unión Europea y España}

La legislación sobre grandes riesgos está armonizada en toda la Unión Europea (En adelante, "UE") porque ha sido introducida por la Directiva Solvencia II, que reformuló varias anteriores e incluye la definición actual de Gran riesgo (artículo 13, n.27). Es también necesario tener en cuenta la Directiva sobre distribución de seguros, conocida como IMD (2), que aplica dicho concepto a los intermediarios de seguros (artículo 12) párrafo 4), así como el Reglamento 593/2008, Ilamado Roma I, sobre la ley aplicable a las obligaciones contractuales (ver artículo 7).

Los riesgos masivos, opuestos a los grandes riesgos, son los riesgos a los que los consumidores están expuestos, por lo tanto, su necesidad de protección es mayor que la de los primeros. Las reglas, que se aplican a los riesgos en masa, intentan asignar la jurisdicción cerca del consumidor. Mientras que las reglas sobre grandes riesgos están orientadas a la "libre elección" por las partes involucradas. La distinción entre riesgos en masa y grandes riesgos es convencional, es decir los Estados miembros de la UE estuvieron de acuerdo con esa distinción. La regulación de la Unión Europea sobre conflictos de leyes incluye los contratos de seguro $^{(3)}$.

En Europa el seguro de grandes riesgos por lo general está sujeto a la ley del país donde

(1) Así me lo informaron varios amigos chilenos que asistieron a la Congreso del CILA en La Habana

(2) Insurance Market Directive (Directiva 2002/92/CE del Parlamento Europeo y del Consejo de 9 de diciembre de 2002)

(3) Estos primeros tres párrafos glosan el mensaje que me enviara el profesor de la Universidad de Milán, Pierpaolo Marano el 5 de mayo de 2015, respondiendo a mi consulta sobre el tratamiento de los 'grandes riesgos' en la Unión Europea 
la aseguradora tiene su lugar habitual de residencia, pero en realidad las partes disfrutan de la libre elección de la ley. Sin embargo, las reglas internacionales obligatorias de acuerdo con el art. 9 Roma I y normas sobre seguro obligatorio según el art. 7 (4) Roma afecta la libre elección de las partes sobre puntos específicos en esos casos. Las partes aceptan que la elección de la ley conllevará las consecuencias de la aplicación de la ley local obligatoria. En otras palabra, las legislaciones europeas permiten a las partes (asegurado y aseguradora) escoger en el contrato la legislación ${ }^{(4)}$ a la que se someten, porque la Directiva de Solvencia II de la Unión Europea, a la que están obligados todos los estados miembros, recoge una definición convencional(5) (corresponde en realidad a lo que podríamos considerar riesgos medianos) de grandes riesgos que busca incentivar las relaciones de aseguramiento entre los países de la Unión Europea, además de que allá el número de grandes riesgos es bastante mayor y muchos de éstos son incluso propietarios de aseguradoras cautivas. En consecuencia, Europa, incluida España, no es ejemplo de países en que se excluya de la aplicación de la LCS a los grandes riesgos como se pretendido sostener ${ }^{(6)}$, espero que por desconocimiento.

España como parte de la Unión Europea se ha adecuado a la Directiva 2009/138/CE del 25 de noviembre de 2009 y en el artículo 44 de la Ley 20/2015 del contrato de seguro ha excluido a los Grandes riesgos de la aplicación imperativa de la norma establecida en los artículos 2 y 3 . Textualmente dicen:

\section{"Artículo 2}

Las distintas modalidades del contrato de seguro, en defecto de Ley que les sea aplicable, se regirán por la presente Ley, cuyos preceptos tienen carácter imperativo, a no ser que en ellos se disponga otra cosa. No obstante, se entenderán válidas las cláusulas contractuales que sean más beneficiosas para el asegurado" (énfasis agregado).

En el artículo 11 de la Ley 20/2015 se establece lo que debe entenderse como Grandes riesgos:
"Artículo 11. Grandes riesgos.

A efectos de lo establecido en esta Ley y en las demás disposiciones reguladoras de la supervisión y contratación de los seguros privados, se entenderá por contratos de seguro de grandes riesgos los siguientes:

a) Los de vehículos ferroviarios, vehículos aéreos, vehículos marítimos, lacustres y fluviales, mercancías transportadas (comprendidos los equipajes y demás bienes transportados), la responsabilidad civil en vehículos aéreos (comprendida la responsabilidad del transportista) y la responsabilidad civil de vehículos marítimos, lacustres y fluviales (comprendida la responsabilidad civil del transportista).

b) Los de crédito y de caución cuando el tomador y el asegurado ejerzan a título profesional una actividad industrial, comercial o liberal y el riesgo se refiera a dicha actividad.

c) Los de vehículos terrestres (no ferroviarios), incendio y elementos naturales, otros daños a los bienes, responsabilidad civil en vehículos terrestres automóviles (comprendida la responsabilidad del transportista), responsabilidad civil en general y pérdidas pecuniarias diversas, siempre que el tomador supere los límites de, al menos, dos de los tres criterios siguientes:

Activo total del balance: 6.200 .000 euros. Importe neto del volumen de negocios: 12.800 .000 euros.

(4) Pero en ningún caso quedan desregulados (sin ley de contrato de seguro que se les aplique).

(5) Los mínimos establecidos en la mencionada directiva, como se verá más adelante, corresponden a riesgos medianos y no a verdaderos 'grandes riesgos', pero lo que pretende es incentivar y facilitar las relaciones inter europeas.

(6) Véase Corzo de la Colina, Rafael y otro. "Seguros de grandes riesgos y protección desproporcionada de los asegurados en la Ley del contrato de seguro". IUS ET VERITAS 54 (julio 2017):100-18. 
Alonso Núñez del Prado Simon

Número medio de empleados durante el ejercicio: 250 empleados.

Si el tomador del seguro formara parte de un grupo de sociedades cuyas cuentas consolidadas se establezcan con arreglo a lo dispuesto en los artículos 42 a 49 del Código de Comercio, los criterios mencionados anteriormente se aplicarán sobre la base de las cuentas consolidadas".

El artículo 44 de la Ley del contrato de seguro 50/1980 a la letra dice:

\section{"Artículo 44(7)}

El asegurador no cubre los daños por hechos derivados de conflictos armados, haya precedido o no declaración oficial de guerra, ni los derivados de riesgos extraordinarios sobre las personas y los bienes, salvo pacto en contrario.

No será de aplicación a los contratos de seguros por grandes riesgos, tal como se delimitan en esta Ley, el mandato contenido en el artículo 2 de la misma".

Sin embargo, lo expuesto no es todo lo establecido en la legislación española y europea para los grandes riesgos como se ha sostenido ${ }^{(8)}$. Es necesario revisar otras normas que se han ignorado, espero que no intencionalmente. Haciendo eco a la a regulación europea, la legislación española excluyó a los grandes riesgos de la aplicación de la ley, no para que no se les aplique ninguna norma, sino para que las partes (asegurado y asegurador) puedan decidir a qué legislación someten el contrato. Esa es la razón por la que la definición europea de grandes riesgos corresponde más bien a lo que en el mercado asegurador se llamaría riesgos medianos. La intención es incentivar el comercio comunitario facilitando la contratación de seguros entre empresas de los estados miembros.
Para el tema de elección de ley aplicable es necesario remitirse al artículo 107.2 de la española Ley del Contrato de Seguro 50/1980 (añadido por el art. 3.6 de la Ley 21/1990, de 19 de diciembre. Ref. BOE-A-1990-30736 y publicado el 20/12/1990, en vigor a partir del $21 / 12 / 1990)^{(9)}$.

\section{“TITULO IV}

Normas de Derecho Internacional Privado

Artículo ciento siete.

1. La ley española sobre el contrato de seguro será de aplicación al seguro contra daños en los siguientes casos:

a) Cuando se refiera a riesgos que estén localizados en territorio español y el tomador del seguro tenga en él su residencia habitual, si se trata de persona física, o su domicilio social o sede de gestión administrativa y dirección de los negocios, si se trata de persona jurídica.

b) Cuando el contrato se concluya en cumplimiento de una obligación de asegurarse impuesta por la ley española.

2. En los contratos de seguro por grandes riesgos las partes tendrán libre elección de la ley aplicable.

3. Fuera de los casos previstos en los dos números anteriores, regirán las siguientes normas para determinar la ley aplicable al contrato de seguro contra daños:

(7) Artículo 44 redactado por Ley 30/1995, 8 noviembre («B.O.E.» 9 noviembre), de Ordenación y Supervisión de los Seguros Privados.

(8) Véase Corzo de la Colina, Rafael y otro. "Seguros de grandes riesgos y protección desproporcionada de los asegurados en la Ley del contrato de seguro".

(9) Se deroga la definición de grandes riesgos del apartado 2 por la disposición derogatoria. a) de la Ley 20/2015, de 14 de julio. Ref. BOE-A-2015-7897. Se modifica por la disposición adicional 6.7 de la Ley 30/1995, de 8 de noviembre. Ref. BOE-A-1995-24262 Se añade por el art. 3.6 de la Ley 21/1990, de 19 de diciembre. Ref. BOE-A-1990-30736. Principio del formulario. Última actualización, publicada el 15/07/2015, en vigor a partir del 01/01/2016. 
Grandes riesgos e información tergiversada e incompleta Big risks and misrepresented and incomplete information

a) Cuando se refiera a riesgos que estén localizados en territorio español y el tomador del seguro no tenga en él su residencia habitual, domicilio social o sede de gestión administrativa y dirección de los negocios, las partes podrán elegir entre la aplicación de la ley española o la ley del Estado en que el tomador del seguro tenga dicha residencia, domicilio social o dirección efectiva.

b) Cuando el tomador del seguro sea un empresario o un profesional y el contrato cubra riesgos relativos a sus actividades realizadas en distintos Estados del Espacio Económico Europeo, las partes podrán elegir entre la ley de cualquiera de los Estados en que los riesgos estén localizados o la de aquél en que el tomador tenga su residencia, domicilio social o sede de gestión administrativa y dirección de sus negocios.

c) Cuando la garantía de los riesgos que estén localizados en territorio español se limite a los siniestros que puedan ocurrir en un Estado miembro del Espacio Económico Europeo distinto de España, las partes pueden elegir la ley de dicho Estado.

4. A los efectos de lo previsto en los números precedentes, la localización del riesgo se determinará conforme a lo previsto en el artículo 1.3, d), de la Ley de Ordenación y Supervisión de los Seguros Privados.

5. La elección por las partes de la ley aplicable, cuando sea posible, deberá expresarse en el contrato o desprenderse claramente de su contenido. Si faltare la elección, el contrato se regirá por la ley del Estado de entre los mencionados en los números 2 y 3 de este artículo, con el que presente una relación más estrecha. Sin embargo, si una parte del contrato fuera separable del resto del mismo y presentara una relación más estrecha con algún otro Estado de los referidos en este número, podrá, excepcionalmente, aplicarse a esta parte del contrato la ley de ese Estado. Se presumirá que existe relación más estrecha con el Estado miembro del Espacio Económico Europeo en que esté localizado el riesgo.

6. Lo dispuesto en los números precedentes se entenderá sin perjuicio de las normas de orden público contenidas en la ley española, cualquiera que sea la ley aplicable al contrato de seguro contra daños. Sin embargo, si el contrato cubre riesgos localizados en varios Estados miembros del Espacio Económico Europeo se considerará que existen varios contratos a los efectos de lo previsto en este número y que corresponden cada uno de ellos únicamente a un Estado".

La cuestión de la jurisdicción está establecida en un Reglamento europeo -aplicable directamente en los 28 estados miembros-y concretamente en sus artículos 15 y 16, en particular su apartado 5. El Reglamento en cuestión, que sustituyó al antiguo Convenio de Bruselas sobre jurisdicción, es el siguiente:

"REGLAMENTO (UE) No. 1215/2012 DEL PARLAMENTO EUROPEO Y DEL CONSEJO de 12 de diciembre de 2012 relativo a la competencia judicial, el reconocimiento y la ejecución de resoluciones judiciales en materia civil y mercantil (Refundición) (DOUE No. L351 20de diciembre de 2012).

\section{SECCIÓN 3}

Competencia en materia de seguros

\section{Artículo 10}

En materia de seguros, se determinará la competencia con arreglo a las disposiciones de la presente sección, sin perjuicio de lo dispuesto en el artículo 6 y en el artículo 7, punto 5.

\section{Artículo 11}

1. El asegurador domiciliado en un Estado miembro podrá ser demandado:

a) ante los órganos jurisdiccionales del Estado miembro donde tenga su domicilio;

b) en otro Estado miembro, cuando se trate de acciones entabladas por el 
Alonso Núñez del Prado Simon

tomador del seguro, el asegurado o un beneficiario, ante el órgano jurisdiccional del lugar donde tenga su domicilio el demandante, o

c) si se trata de un coasegurador, ante los órganos jurisdiccionales del Estado miembro que conozcan de la acción entablada contra el primer firmante del coaseguro.

2. Cuando el asegurador no esté domiciliado en un Estado miembro pero tenga sucursales, agencias o cualquier otro establecimiento en un Estado miembro se le considerará, para los litigios relativos a su explotación, domiciliado en dicho Estado miembro.

\section{Artículo 12}

El asegurador podrá, además, ser demandado ante el órgano jurisdiccional del lugar en que se haya producido el hecho dañoso cuando se trate de seguros de responsabilidad o de seguros relativos a inmuebles. La misma regla será de aplicación cuando se trate de seguros que se refieren a inmuebles y a bienes muebles cubiertos por una misma póliza y afectados por el mismo siniestro.

\section{Artículo 13}

1. En materia de seguros de responsabilidad civil, el asegurador podrá ser demandado, en el marco de acciones acumuladas, igualmente ante el órgano jurisdiccional que conozca de la acción de la persona perjudicada contra el asegurado, cuando la ley de este órgano jurisdiccional lo permita.

2. Los artículos 10, 11 y 12 serán aplicables en los casos de acción directa entablada por la persona perjudicada contra el asegurador cuando la acción directa sea posible.

3. El mismo órgano jurisdiccional será competente cuando la ley reguladora de esta acción directa prevea la posibilidad de demandar al tomador del seguro o al asegurado.

\section{Artículo 14}

1. Salvo lo dispuesto en el artículo 13, apartado 3, la acción del asegurador solo podrá ser ejercitada ante los órganos jurisdiccionales del Estado miembro en cuyo territorio esté domiciliado el demandado, ya sea tomador del seguro, asegurado o beneficiario.

2. Lo dispuesto en la presente sección no afectará al derecho de formular una reconvención ante el órgano jurisdiccional que conozca de la demanda inicial de conformidad con la presente sección.

\section{Artículo 15}

Únicamente prevalecerán sobre las disposiciones de la presente sección los acuerdos:

1) posteriores al nacimiento del litigio;

2) que permitan al tomador del seguro, al asegurado o al beneficiario formular demandas ante órganos jurisdiccionales distintos de los indicados en la presente sección;

3) que, habiéndose celebrado entre un tomador de seguro y un asegurador, ambos domiciliados o con residencia habitual en el mismo Estado miembro en el momento de la celebración del contrato, atribuyan, aunque el hecho dañoso se haya producido en el extranjero, competencia a los órganos jurisdiccionales de dicho Estado miembro, a no ser que la ley de este prohíba tales acuerdos;

4) celebrados con un tomador de seguro que no esté domiciliado en un Estado miembro, a no ser que se trate de un seguro obligatorio o se refiera a un inmueble sito en un Estado miembro, o

5) que se refieran a un contrato de seguro que cubra uno o varios de los riesgos enumerados en el artículo 16.

\section{Artículo 16}

Los riesgos contemplados en el artículo 15, punto 5, son los siguientes: 
Grandes riesgos e información tergiversada e incompleta Big risks and misrepresented and incomplete information a) buques de navegación marítima, instalaciones costeras y en alta mar o aeronaves, causado por hechos sobrevenidos en relación con su utilización para fines comerciales;

b) mercancías distintas de los equipajes de los pasajeros, durante un transporte realizado por dichos buques o aeronaves, bien en su totalidad o bien en combinación con otros modos de transporte;

2) toda responsabilidad, con excepción de la derivada de los daños corporales a los pasajeros o de los daños a sus equipajes:

a) resultante de la utilización o la explotación de los buques, instalaciones o aeronaves, de conformidad con el punto 1, letra a), cuando la ley del Estado miembro en el que esté matriculada la aeronave no prohíba los acuerdos atributivos de competencia en el aseguramiento de tales riesgos;

b) por las mercancías durante uno de los transportes contemplados en el punto 1, letra b);

3) toda pérdida pecuniaria ligada a la utilización o a la explotación de buques, instalaciones o aeronaves de conformidad con el punto 1, letra a), en particular la del flete o el beneficio del fletamento;

4) todo riesgo accesorio a cualquiera de los contemplados en los puntos 1 a 3 ;

5) no obstante lo dispuesto en los anteriores puntos 1 a 4 , todos los "grandes riesgos» industriales y comerciales, tal como se enumeran en la Directiva 2009/138/CE del Parlamento Europeo y del Consejo, de 25 de noviembre de 2009 , sobre el seguro de vida, el acceso a la actividad de seguro y de reaseguro y su ejercicio (Solvencia II) (14)

\subsection{Chile}

Salvo el caso de Chile, en ningún otro país del mundo se excluye a los grandes riesgos de la aplicación de la Ley de contrato de seguro y en Latinoamérica ni siquiera se les separa, probablemente, porque no somos un caso similar al europeo en que las empresas contratan pólizas con aseguradoras de otros países de la región, sino por lo general con compañías locales. El caso chileno es un ejemplo patético, ya que allá la norma (artículo 542 de la Ley 20667, que regula el contrato de seguro y reemplaza el título VIII del Libro II del Código de Comercio, publicada el 9 de mayo de 2013) definió los grandes riesgos como los seguros de daños contratados por una persona jurídica que paguen una prima anual superior a 200 unidades de fomento, es decir alrededor de 7,200.00 dólares. Incluyó además a los seguros de casco y transporte marítimo y aéreo. Resulta evidente que una empresa que pague, por ejemplo, 10,000.00 dólares de prima no puede ser considerada como gran riesgo, es más ni siquiera como mediano.

Lo que en verdad se hizo en el país del sur es unificar a los riesgos medianos y grandes bajo el engañoso nombre de grandes riesgos, usado en la regulación europea, excluyéndolos de la aplicación de la ley y dejándolos al descubierto de cualquier tutela. Se usó el término 'grandes riesgos' para proceder de una forma poco equitativa y que no tiene parangón en ninguna otra parte del mundo. Pareciera que las aseguradoras condicionaron la aprobación de la ley (que tenía muchos años de espera) a la inclusión de este artículo que es a todas luces abusivo y lesivo a los intereses de la mayor parte de empresas aseguradas que han quedado sometidas a los textos de las pólizas que, además, no tienen posibilidad de discutir.

Para hablar de un mercado que conozco y que no debe ser muy diferente en este aspecto al chileno, si en el Perú habláramos de primas tendríamos que pensar en un mínimo de 5 millones de dólares. Recién con una prima anual de ese volumen en la actualidad una empresa asegurada está en capacidad de negociar en igualdad de condiciones con la aseguradora. Lo expuesto sólo demuestra 


\section{Alonso Núñez del Prado Simon}

la gran influencia que tienen en Chile los aseguradores para haber logrado el límite indicado, que es lo que se pretendió lograr aquí en el Perú y que a todas luces hubiera sido un abuso.

En ningún otro país la Ley de contrato de seguro está expresamente limitada a amparar sólo a las personas naturales y a las MYPES, como se pretendió en el Perú con el Proyecto de Ley 4635/2014-CR y ocurre, parcialmente, con nuestro Código de Protección al Consumidor que en realidad incluye a empresas más grandes siempre que se adecúen a la definición de consumidor ${ }^{(10)}$.

\subsection{El caso de Perú}

Cuando fue consultada por el Congreso antes de la aprobación y promulgación de la LCS, la SBS copiando la ley española, como lo hizo en la mayor parte de sus sugerencias, había propuesto un tratamiento diferenciado a los 'grandes riesgos' dentro de la propia norma, suponiendo que ésta le delegaría la definición, pero en la Comisión que redactó el Proyecto optamos por una alternativa diferente, por la enorme influencia que tienen las aseguradoras en esta institución en el Perú, y que probablemente resultaría en límites muy bajos, como ocurre en el país del sur, que además no se actualizarían oportunamente, terminando por excluir a un importante número de negocios asegurados de los beneficios de la ley.

La solución escogida por la Ley 29946 es remitirse a las pólizas, ya que los otros criterios, como el volumen de activos, capital, montos de primas o número de empleados, pueden ser engañosos. Entonces cuando se pregunta ¿con qué criterio se haría el control difuso respecto de los grandes riesgos?, la respuesta es que, como lo establece el artículo III de la Ley 29946, el criterio es el texto de la póliza (wording en inglés). Si éste es el redactado por el asegurador, significa que el contrato se ha realizado por adhesión y tiene que tener todas las protecciones de la ley. Si por el contrario contiene cambios, el juez o árbitro tendrá que decidir sobre la importancia de éstos y resolver hasta donde corresponde considerar el contrato como de adhesión y por tal también hasta donde debe contar con las protecciones de la ley. Este camino evita que haya empresas que resulten no amparadas por la ley, pero que en la realidad no estén en capacidad de cambiar ni una coma del contrato redactado por el asegurador.

A pesar de que se ha explicado públicamente la forma de limitar (no excluir como alguien ha sostenido (Corzo de la Colina, 105), la aplicación de nuestra ley a los grandes riesgos, las aseguradoras consiguieron que la SBS apoyara mediante un oficio el Ante-Proyecto de excluirlos totalmente mediante una norma modificatoria que, originalmente, no prosperó ni siquiera en la bancada del congresista que la promovía y que momentáneamente quedó en nada, aunque como vaticiné las compañías insistieron e intentarán pasarla entre gallos y medianoche.

Teniendo en cuenta que tal como quedó al final la ley en el Perú, salvo en los seguros personales, obligatorios y masivos, las pólizas son redactadas y también modificadas por las aseguradoras sólo registrándolas en la SBS, y que no estamos en el caso de Europa donde las empresas contratan sus pólizas de seguros con aseguradoras de países vecinos a cuyas legislaciones las partes puedan decidir someterse-en la Comisión consideramos que la mejor manera de afrontar el problema era la que he expuesto y que materializamos en el ya mencionado artículo III de las Disposiciones

(10) “Ley 29571

Artículo IV.- Definiciones del Código de Protección y Defensa del Consumidor

1. Consumidores o usuarios

1.1 Las personas naturales o jurídicas que adquieren, utilizan o disfrutan como destinatarios finales productos o servicios materiales e inmateriales, en beneficio propio o de su grupo familiar o social, actuando así en un ámbito ajeno a una actividad empresarial o profesional. No se considera consumidor para efectos de este Código a quien adquiere, utiliza o disfruta de un producto o servicio normalmente destinado para los fines de su actividad como proveedor" (Énfasis agregado). 
Grandes riesgos e información tergiversada e incompleta Big risks and misrepresented and incomplete information
Generales (Título I) de la Ley 29946 donde establecimos que:

"El contrato de seguro se celebra por adhesión, excepto en las cláusulas que se hayan negociado entre las partes y que difieran sustancialmente con las pre redactadas".

Como se puede ver, en vez de guiarnos por el capital, volumen de ventas, número de empleados, sumas aseguradas o primas esta alternativa se remite a la realidad concreta, el texto objetivo de la póliza. En éste se puede ver si, efectivamente, el asegurado (empresa grande o pequeña) ha sido capaz de negociar de igual a igual con la compañía y cambiar el condicionado pre-redactado por la aseguradora. En otras palabras, por este camino no hay duda y en el caso de que el asegurador sostenga que el asegurado negoció de igual a igual tiene que demostrarlo con las modificaciones que logró al redactar el contrato.

En el Perú, como ya he indicado, las empresas que logran que las aseguradoras cambien los términos pre-redactados se pueden contar con los dedos de la mano y en esos casos les resultará muy fácil demostrarlo (basta con la presentación de las pólizas), lo que de ninguna manera constituye un elevado estándar de prueba como se ha sostenido (Corzo 2017, 106).

Conviene dejar claro que es usual que se incluyan cláusulas que modifican las condiciones generales, pero estas condiciones especiales son también pre-redactadas por la compañía, aunque a veces éstas aceptan pequeñas modificaciones que son los textos preparados por los grandes corredores para todos sus clientes y que buscan diferenciar la calidad de su servicio. Como es de suponer tampoco las condiciones particulares (nombre y suma asegurada, etcétera.) que individualizan el riesgo, pueden considerarse como importantes modificaciones que le quiten la calidad de contrato por adhesión a una póliza.

Consideramos que este camino constituía una mejor opción legislativa porque además no excluye a los 'grandes riesgos' de la aplicación de ley, sino que sólo aligera la interpretación contra stipulatorem ${ }^{(11)}$ y deja a criterio del juez o árbitro sólo en los casos de conflicto (proporcionalmente muy pocos) la decisión de cómo aplica los beneficios de la norma, además de que permite separar las cláusulas 'negociadas' de las 'pre-redactadas' y no excluir de los beneficios de la ley a un asegurado que, eventualmente, pudo haber logrado pactar alguna cláusula aislada o que, de haberse optado por el otro camino, excediera los límites fijados por la institución supervisora, aun cuando no hubiera tenido ninguna posibilidad de negociar los términos y condiciones de su póliza.

Tiene también la virtud de separar las diferentes pólizas de un mismo cliente, ya que éste podría tener pólizas en los que ha logrado negociar de igual a igual, pero otras en que esto ha sido imposible por las condiciones del mercado. La objeción que sostiene que genera inseguridad jurídica (Corzo 2017, 107) no resiste análisis, ya que en cualquier litigio será evidente cuando se ha logrado conseguir importantes modificaciones al texto pre-redactado por la aseguradora y repito no enerva mayor carga probatoria (sólo el texto de la póliza).

Otra crítica que dice que sería un camino para judicializar los casos carece de sustento, porque nadie va a llevar a litigio algo que con la sola presentación del condicionado de la póliza quedará desvirtuado. Sin duda habrá casos en que se discutirá la importancia de la modificación lograda, pero serán los menos y muy pequeños en número.

Se ha afirmado que un asegurado podría tener la capacidad de hacer cambios en los términos de su póliza y dejaría de hacerlos para lograr la protección de la LCS (Corzo 2017, 107). Esto es suponer que las personas actúan contra sus propias conveniencias.

Es mejor que mi póliza por ejemplo diga que se cubre bajo la cláusula de ausencia

(11) También llamada 'contra proferentem'. 


\section{Alonso Núñez del Prado Simon}

de control no sólo los casos en que el chofer haya ingerido alcohol, sino también cualquiera otro acto irresponsable que pudiera cometer, que discutirlo después como cláusula abusiva al amparo de la LCS. Una persona preferirá, casi sin excepción, que su contrato diga algo expresamente a someterse a la interpretación futura de una norma. No creo que nadie prefiera dejar de usar su poder de negociación para equilibrar un contrato de seguros a todas luces asimétrico. Además, parece que no se hubiera leído con detenimiento el texto del artículo III de LCS que dice "el contrato de seguro se celebra por adhesión, excepto las cláusulas que se hayan negociado entre las partes y que difieran sustancialmente con las pre-redactadas", lo que significa que la existencia de una cláusula evidentemente negociada no convierte a todo el contrato en paritario, seguirá siendo por adhesión salvo en esa cláusula. Tendrían que haber muchas para que el íntegro del contrato pueda ser entendido como paritario. El argumento que pretende descalificar el enfoque de la norma y específicamente del artículo III a partir del posible comportamiento de los asegurados y las aseguradoras se derrumba por sí mismo si tenemos presente que se legisla suponiendo la buena fe y no la mala.

Como era de suponer, la opción que escogimos en la Comisión, como la LCS misma, a la que se opusieron y boicotearon de manera taimada (diciendo que sí pero no, como lo muestra su comunicación respondiendo la consulta del Congreso de la República) no es del agrado de las aseguradoras y por eso intentaron hacer modificaciones. Al final el problema es que la nueva ley les ha restado poder y ahora ya no pueden hacer y deshacer como antes, sino que tienen que someterse a algunas reglas que, por fortuna, son protectoras del asegurado porque, como he indicado y todos sabemos, el contrato de seguro es asimétrico. Una de las partes es la que conoce del negocio y la que redacta el contrato, además de que con el tiempo lo va 'afinando' y haciendo exclusiones y creando restricciones que muchas veces reducen los límites de cobertura, lo que debería estar prohibido.

Otro argumento que las aseguradoras han esgrimido es la dificultad que les causa la Ley 29946 en la negociación de reaseguros. Cabe preguntarles ¿por qué los demás países latinoamericanos no tienen ese problema?, y ¿por qué los europeos, que tienen leyes más protectoras de los asegurados que la nuestra, tampoco los tienen? En la industria hay que entender a los reaseguradores como proveedores de las aseguradoras; en consecuencia, el público, es decir los asegurados, no tiene por qué ser afectados por las condiciones que éstas consigan. Esa es la razón por la que el artículo 322 de la Ley 26702 General del Sistema Financiero y orgánica de la SBS establece que existe completa independencia entre los contratos de seguros y reaseguros.

De otro lado, es relevante recordar que, salvo excepciones, los reaseguradores se someten a las leyes de los países de las compañías que reaseguran; es más, hay casos como Brasil en los que por ley los contratos de reaseguro están sometidos a la jurisdicción y las leyes del país del domicilio de la compañía reasegurada.

Asimismo, algo que desde hace varios años resulta incómodo al contratarse reaseguros $-y$ que las aseguradoras locales hacen lo posible por evitar y casi nunca aceptan- es que el reasegurador les imponga una jurisdicción y legislación extranjeras para el contrato, lo que obliga a que en caso de conflicto la aseguradora tenga que ir a litigar en otro país. Esto pudo evitarse si se hubiera incluido en la ley el artículo que obligaba a que los contratos de reaseguros estuvieran sometidos a la ley y jueces peruanos, pero que fue eliminado, porque la SBS, equivocadamente, creía que la mayor parte de contratos facultativos están sujetos a leyes y tribunales extranjeros, cuando, más bien, rara vez ocurre ${ }^{(12)}$.

(12) He consultado personalmente con los principales brókeres de reaseguros (Marsh, Aon, JLT, Guy Carpenter, Willis, etc.) y me lo han confirmado. 
Grandes riesgos e información tergiversada e incompleta Big risks and misrepresented and incomplete information

\section{El rol protector del Estado en el contrato de seguro}

A lo antes expuesto hay que agregar que la actividad aseguradora tiene características muy especiales derivadas del hecho de ser un negocio que administra fondos del público es decir de los asegurados. Como es ampliamente conocido, el contrato de seguro no puede darse en términos individuales, ni siquiera de un número pequeño de personas o empresas, ya que fundado en la ley de los grandes números requiere de la participación de un importante grupo de asegurados quienes aportan a un fondo común que durante la vigencia sirve para pagar las pérdidas que tengan algunos de ellos. Así se aclara que las aseguradoras son simples administradoras de esos fondos, que son independientes entre sí de acuerdo al ramo de seguro de que se trate.

En otras palabras, los siniestros no se pagan con dinero de las compañías, sino con las primas que pagaron los otros asegurados del ramo en el que hayan contratado su póliza (incendio, robo, automóviles, responsabilidad civil, etcétera). $Y$ ese es el fundamento de que la actividad aseguradora, como la bancaria, financiera y de fondos de pensiones sea supervisada por mandato del artículo 87 de la Constitución peruana. También es la razón por la que en todos los países existe una ley del contrato de seguro, que busca equilibrar las evidentes asimetrías que se dan en esta modalidad de contrato (la aseguradora no solo redacta las condiciones de la póliza, sino que es la que conoce profundamente el negocio). Es evidente que la intención no es convertir el contrato en simétrico, lo que sería imposible, sino más bien como acabo de señalar en equilibrarlo dentro de lo posible.

Lo que acabo de exponer es la razón por la que el rol protector del Estado tiene un carácter especializado y diferente a otros productos o servicios y, en consecuencia, es argumento válido (contra lo que se ha opinado (Corzo de la Colina, 106) para que exista una tutela especial y diferente como en todos los países civilizados. Recordemos que nuestra LCS es muy similar a la española y a la alemana y en general a las más modernas legislaciones sobre seguros en el mundo donde también existen Códigos de Protección al Consumidor, pero siempre hay una ley del contrato de seguro.

El supuesto encarecimiento de las primas que supuestamente ocasionaría la LCS ha sido desvirtuado por la realidad.
Después de más de cuatro años de vigencia de la LCS las primas han bajado sustancialmente y no por la norma, sino como parte de los ciclos en los costos de los reaseguros del mundo. Nuestro país representa bastante menos del $1 \%$ del total de las primas mundiales y tiene uno de los niveles más bajos de penetración en la región. Parte de la explicación a esta realidad estuvo en la falta de protección al consumidor. Las compañías de seguros todavía hoy tienen una pésima imagen dentro del público en el Perú derivada de la incapacidad de los asegurados, por falta de instrumentos legales, para reclamar frente a sus abusos y rechazos, especialmente los más pequeños.

Lamentablemente, el enfoque de algunos de los ejecutivos que asumieron la dirección de las principales compañías ha llevado a la industria a olvidar su importante rol social. Antes la idea era hacer utilidades administrando con eficiencia el negocio, esto es suscribiendo bien, pero pagando los siniestros cuando ocurrían; ahora la idea es vender todos los seguros posibles y rechazar la mayor parte de los reclamos que se pueda en busca de mayores utilidades en el corto plazo. Por ese camino la penetración no va a aumentar. El crecimiento de la industria en las últimas décadas tiene explicación en la liberalización del mercado, el desarrollo económico y en especial en los seguros previsionales, no en el pésimo manejo de la mayor parte de compañías enfocadas en hacer la mayor cantidad de utilidades a fin del año que transcurre.

Cuando se construye un castillo sobre cimientos de barro, termina por derrumbarse. Siendo falso que la normativa europea y la legislación española excluyan a los 'grandes riesgos' de las leyes de contrato de seguros vigentes en esos países, el sustento en la legislación comparada se cae, dejando sólo el caso de Chile que a todas luces es un 


\section{Alonso Núñez del Prado Simon}

abuso que carece de argumentos racionales y que más temprano que tarde terminará por desaparecer.

\section{Referencias bibliográficas}

Bickelhaup, David. 1983. General Insurance. Richard D. Irwin Inc. Illinois.

Bustamante Ferrer, Jaime. 1983. Manual de Principios Jurídicos del Seguro. Bogotá: Editorial Temis.

Curso de seguros - Chartered Insurance Institute. 1973. Elementos de Seguros. Madrid: Editorial Mapfre.

Corzo de la Colina, Rafael y otro. 2017. Seguros de grandes riesgos y protección desproporcionada de los asegurados en la Ley del contrato de seguro. IUS ET VERITAS 54 (julio 2017):100-108. https://doi.org/10.18800/ iusetveritas.201702.004
Efrén Ossa, G. J. 1984. Teoría General del Seguro. Bogotá: Editorial Temis.

Efrén Ossa, G. J. 1963. Tratado Elemental de Seguros. Bogotá: Editorial Leonor.

Halperin, Isaac. 1983. Lecciones de Seguros. Buenos Aires: Ed. Depalma.

Lorimer, James y otros. 1981. The Legal Environment of Insurance. $2^{\mathrm{a}}$ ed. Pensylvania: American Institute for Property and Liability Underwriters Inc.

Mehr, Robert I. 1983. Fundamentals of Insurance. Richard D. Irwing, Inc. Illinois.

Soler Aleu, Amadeo. 1978. El Nuevo Contrato de Seguros. Buenos Aires: Ed. Astrea.

Stiglitz, Rubén. S. 1980. El Siniestro. Buenos Aires: Ed. Astrea.

Stiglitz, Rubén S. 2004. Contrato de Seguros. Buenos Aires: La Ley. 